\title{
EJSBS
}

The European Journal of Social \&

Behavioural Science

ISSN: 2301-2218 (ONUNE)
OPEN ACCESS

\section{KNOWLEDGE, ATTITUDE AND PERCEPTIONS TOWARDS BASIC LIFE SUPPORT TRAINING AMONG STUDENT TEACHERS IN A MALAYSIAN UNIVERSITY}

${ }^{a}$ Faculty of Education, Universiti Teknologi MARA (UiTM) Cawangan Selangor Kampus Puncak Alam, Malaysia

${ }^{b}$ Faculty of Health Sciences, Universiti Kebangsaan Malaysia (UKM), Wilayah Persekutuan Kuala Lumpur, Malaysia

\begin{abstract}
Basic Life Support (BLS) training for school teachers is increasingly acknowledged as an important public health method to disseminate knowledge regarding life-saving skills such as CPR. However, there is a lack of studies examining this crucial area of training in Malaysia. Hence, this study aimed to investigate student teachers' knowledge, attitudes, and perceptions towards Basic Life Support training in a public university in Malaysia. An online questionnaire was implemented among finalyear student teachers spanning seven different majors. Participants were required to answer 40 questions regarding their CPR knowledge, attitudes towards obtaining BLS training, and perceptions towards performing CPR. A total of 111 student teachers $(80.2 \%$ female) responded to the survey. Results indicated that the majority of the participants $(98.2 \%)$ would like to join a CPR training if offered. However, most participants reported a lack of information or resources in obtaining CPR training (82.0\%) and had fears of incurring injury (93.7\%), being sued (96.4\%), being uncomfortable about bodily fluids $(85.6 \%)$, or concerns of being infected with a communicable disease $(85.6 \%)$ by the individual receiving CPR. Notably, knowledge regarding CPR was low regardless of CPR training history. Therefore, there is a need for public health information to be disseminated regarding CPR to dispel fears regarding its practice and provide future teachers opportunities to obtain BLS training.
\end{abstract}

Keywords: Basic Life Support, CPR, training, knowledge, attitude, student-teacher, Malaysia

(C) 2021 Published by European Publisher. www.europeanpublisher.com

* Corresponding author Tel: +603-32584920

E-mail address: fariduddin@uitm.edu.my 
https://doi.org/10.15405/ejsbs.295

eISSN: 2301-2218 / Corresponding Author: Muhamad Nur Fariduddin

Selection \& Peer-review under responsibility of the Editors

\section{Introduction}

To date, an estimated 17.5 million people have died each year from cardiovascular diseases (CVD) such as stroke and heart attack, known to be the world's leading cause of death (Field et al., 2010). Out of hospital cardiac arrests (OHCA) is a significant public health concern accounting for a substantial number of deaths worldwide. OHCA occurs in all groups, from adults to infants, comprising $70 \%$ of high mortality risk cases outside hospital settings (Dwood et al., 2014; Rajeswaran et al., 2018). As CPR is considered the second link in the chain of survival, it is highly recommended that this vital life-saving technique be taught and practiced worldwide as it improves the victim's survival rate when properly administered by a trained individual before the arrival of medical personnel (Hazinski et al., 2010; Nolan et al., 2010). A skilled individual's quick response could save a victim's life when performed accurately and effectively (Cuijpers et al., 2016; Plotnikoff \& Moore, 1989).

The teaching of CPR, now extended to secondary school students, is being increasingly encouraged worldwide (Reder \& Quan, 2003). As students are in school for a significant period of the day, basic CPR knowledge is essential (Olympia et al., 2005). These skills are now being taught as an optional component of the curriculum in primary and secondary schools in some countries (Adedamola \& Chukwudi, 2018; Ghrayeb et al., 2017). The guidelines of the International Liaison Committee on Resuscitation (ILCOR) by the American Academy of Paediatrics and American Heart Association (AHA) strongly recommends the inclusion of the BLS syllabus in the school curriculum (Adedamola \& Chukwudi, 2018; Jain et al., 2016). The American Academy of Paediatrics and AHA have issued guidelines that stress the need for school teachers to be knowledgeable about emergency response measures to address lifethreatening emergencies (Olympia et al., 2005). Thus, in this regard, the training of school teachers will facilitate the learning process for students.

School teachers form an integral part of our society, as they are responsible for educating future generations. Heightened awareness among school teachers will enhance their students' knowledge, which the students can share with their family, creating a ripple effect and increasing awareness in the community. In the long run, such educative processes can contribute significantly to an increase in the number of individuals trained to perform CPR when necessary (Adedamola \& Chukwudi, 2018; Jain et al., 2016). Research has shown that school teachers are expected to play a vital role in performing CPR on students in any medical emergency. This means that teachers should acquire adequate knowledge and skills to provide effective resuscitation. Within the confines of the school, they are often the immediate individual on the scene to identify cardiac arrest in an individual (Zinckernagel et al., 2016). Malaysia has over 10,000 schools with an estimated 5 million students enrolled, including 
https://doi.org/10.15405/ejsbs.295

eISSN: 2301-2218 / Corresponding Author: Muhamad Nur Fariduddin

Selection \& Peer-review under responsibility of the Editors

420,000 teachers employed from pre-school to high school (Ministry of Education, n.d.). However, today's Malaysian school curriculum still lacks such topics, together with the resources to implement teaching ("Make emergency first aid a compulsory subject in schools," 2019).

Lukas et al. (2016) reported that teachers are as effective as physicians in teaching CPR to school children. Their study revealed that over $90 \%$ of school teachers who led the training had confidence in teaching their students. Some studies however, revealed that $50 \%$ of teachers were unwilling to teach CPR because they lacked knowledge (Mpotos et al., 2013) and CPR teaching skills (Tanaka et al., 2011). It is natural that teachers expect to be trained adequately in order to be able to teach students; however, teachers' actual CPR capacity has rarely been documented in the literature. Several international studies have reported on teachers' knowledge and attitudes regarding BLS and CPR practice in the school setting (Alharbi et al., 2016; Ghrayeb et al., 2017).

\section{Purpose of the Study}

Due to the lack of data in non-Western settings, such as in Malaysia, this initial survey was conducted to determine the knowledge, attitude, and perceptions towards basic life support training among student teachers in a Malaysian university.

\section{Research Questions}

The present study seeks to:

3.1 investigate the level of cardiopulmonary resuscitation (CPR) knowledge among student teachers from the Faculty of Education, Universiti Teknologi (MARA) Selangor.

3.2 investigate the attitude towards cardiopulmonary resuscitation (CPR) training among student teachers from the Faculty of Education, Universiti Teknologi (MARA) Selangor.

3.3 investigate the perception in rendering cardiopulmonary resuscitation (CPR) during medical emergency among student teachers from the Faculty of Education, Universiti Teknologi (MARA) Selangor. 
https://doi.org/10.15405/ejsbs.295

eISSN: 2301-2218 / Corresponding Author: Muhamad Nur Fariduddin

Selection \& Peer-review under responsibility of the Editors

\section{Materials \& Methods}

\subsection{Research Design}

A cross-sectional quantitative survey design was employed involving final semester undergraduate student teachers across seven different majors from the Faculty of Education, Universiti Teknologi (MARA) Selangor.

\subsection{Setting and Sample}

This study was conducted between December 1, 2020, and January 31, 2021, for a total of nine weeks. The samples were recruited from all undergraduate departments, using convenience sampling with 256 student teachers ranging from seven different majors enrolled in their final semesters. The inclusion criteria included being final semester undergraduate student teachers from all majors from the Faculty of Education of Universiti Teknologi MARA (UiTM) located in Selangor. The Faculty Ethical Committee reviewed and approved this study [UiTM/200-FP(PT.3/3)]. The questionnaire outline was described accordingly, and consent was acquired by submitting the online forms.

\subsection{Data Collection Procedure}

Knowledge in CPR, attitudes, and perceptions towards BLS was assessed using an online platform via google form. With the Registrar's assistance. the questionnaire was distributed through an email invitation sent to all final semester student teachers. All students were given two weeks to complete the questionnaire. A reminder was set twice by the department coordinators to remind the students to submit the completed questionnaire.

\subsection{Research Instruments}

The questionnaire comprised a total of 40 questions across three categories, including socio-demographics. Knowledge of CPR was obtained in a 20-item Multiple Choice Question section. The questions were based on the theory of the BLS Resuscitation Guidelines (Adult, Child \& Infant) by the AHA and previously validated by selected professionals in terms of its face validity, construct, criterion, content validity, and tested in several studies for its reliability (Fariduddin et al., 2018; 2019; 2020). A passing mark of 84\% (16 out of 20) for the MCQ was adopted in this study, consistent with the official AHA guidelines. One mark was awarded for each correct answer, while no penalty was given for incorrect answers. Attitude and perception were assessed using a dichotomous scale, comprising 12 items. This set of items was adopted and adapted from Pivac et al. (2020) and Ojifinni et al. (2019). The content and face validity 
for both instruments were previously established, with an internal consistency reliability of Cronbach's alpha 0.81 (Pivac et al., 2020) and 0.72 (Ojifinni et al., 2019) respectively.

\subsection{Data Analysis}

All data collected from the returned questionnaires were extracted and imported into IBM SPSS Version 27 software for analysis. The demographic information was reviewed, organized, tabulated, and statistically analyzed using descriptive statistics and the CPR knowledge test scores. A chi-square test of contingencies was used to analyze the association between the last CPR certification and CPR knowledge scores.

\section{Results}

Table 1. Respondents' demographic characteristics

\begin{tabular}{|c|c|c|}
\hline Demographics & Descriptions & $\mathrm{n}(\%)$ \\
\hline \multirow[t]{2}{*}{ Gender } & Male & $22(19.8)$ \\
\hline & Female & $89(80.2)$ \\
\hline \multirow[t]{3}{*}{ Age } & $19-21$ & $1(0.9)$ \\
\hline & $22-24$ & $55(49.5)$ \\
\hline & $>25$ & $55(49.5)$ \\
\hline \multirow[t]{2}{*}{ Highest Level of Education } & STPM $^{1 /}$ Matriculation & $14(12.6)$ \\
\hline & Diploma & $97(87.4)$ \\
\hline \multirow[t]{7}{*}{ Course Information } & TESL $^{2}$ & $38(34.2)$ \\
\hline & Physics Education & $7(6.3)$ \\
\hline & Chemistry Education & $11(9.9)$ \\
\hline & Biology Education & $20(18.0)$ \\
\hline & Mathematics & $5(4.5)$ \\
\hline & Physical \& Health & $15(13.5)$ \\
\hline & Art Education & $15(13.5)$ \\
\hline \multirow[t]{2}{*}{ Experienced Dealing with Emergencies } & Yes & $35(31.5)$ \\
\hline & No & $76(68.5)$ \\
\hline \multirow{2}{*}{$\begin{array}{l}\text { Attended the First Aid Course for the past five } \\
\text { years }\end{array}$} & Yes & $53(47.7)$ \\
\hline & No & $58(52.3)$ \\
\hline \multirow[t]{3}{*}{ Last CPR Course Certification } & $<6$ months & $56(50.5)$ \\
\hline & $7-12$ months & $4(3.6)$ \\
\hline & $>1$ year & $51(45.9)$ \\
\hline \multirow[t]{8}{*}{ Source of CPR Training } & Healthcare & $5(4.5)$ \\
\hline & Professionals & $21(18.9)$ \\
\hline & Lectures & $7(6.3)$ \\
\hline & NGO's & $17(15.3)$ \\
\hline & Internet/Television & $28(25.2)$ \\
\hline & Co-curriculum & $33(29.7)$ \\
\hline & Activities & \\
\hline & Multiple Sources & \\
\hline
\end{tabular}

${ }^{1}$ STPM is the Malaysian version of Higher School Certificate A levels.

2 Teaching of English as a Second Language 
Out of 256 questionnaires distributed through an online platform (Table 1), a total of 111 were returned and analyzed, with a response rate of $43.4 \%$. Most respondents were female (n $=89 ; 80.2 \%)$, with $22(19.8 \%)$ males. There were three age categories, with $1(0.9 \%)$ respondent aged between 19-21 and 110 (99\%) respondents aged between 22-24 ( $\mathrm{n}=55$; $49.5 \%)$ and above $25(\mathrm{n}=55 ; 49.5 \%)$. Most respondents had a diploma $(\mathrm{n}=97 ; 87.4 \%)$, and $14(12.6 \%)$ were STPM/ Matriculation holders. The majority of respondents were $38(34.2 \%)$ from TESL, 7 (6.3\%) from Physics, 11 (9.9\%) from Chemistry, 20 (18\%) from Biology, 5 (4.5\%) from Mathematics, and 15 (13.5\%) each from Physical \& Health and Art Education respectively.

As for CPR background, 76 (68.5\%) had not handled any medical emergencies before, with $58(52.3 \%)$ had never attended any CPR-related course for the past five years. However, $56(50.5 \%)$ obtained their recent CPR certification in less than six months, followed by 4 (3.6\%) within 7-12 months, and 51 (45.9\%) obtained their certification more than a year ago. All respondents acquired their training either through multiple sources $(n=33 ; 29.7 \%)$, cocurriculum activities $(n=28 ; 25.2 \%)$, internet $(n=17 ; 15.3 \%)$, lectures $(n=21 ; 18.9 \%)$, NGOs $(\mathrm{n}=7 ; 6.3 \%)$ and healthcare professionals $(\mathrm{n}=5 ; 4.5 \%)$.

Table 2. Respondents' Basic Life Support (BLS) knowledge scores

\begin{tabular}{ccc}
\hline Variables & Scoring & $\mathrm{N}(\%)$ \\
\hline BLS Knowledge & Pass & $0(0)$ \\
& Fail & $111(100)$ \\
& Mean & S.D \\
& 6.59 & 2.21 \\
\hline
\end{tabular}

The first part of the questionnaire examined the level of BLS knowledge among all student teachers. The mean knowledge scores were $6.59 \pm 2.21$ out of a maximum of 20 points. None of the students passed the knowledge test. Notably, a Pearson chi-square test of contingencies used to examine the association between BLS scoring status (PASS/FAIL) and last CPR course certification alarmingly found that the failing rate of all students indicates no significant association towards the previous CPR certification despite more than half of the respondents having reported that they had acquired a recent CPR certification in the last six months (Table 2). 
https://doi.org/10.15405/ejsbs.295

eISSN: 2301-2218 / Corresponding Author: Muhamad Nur Fariduddin

Selection \& Peer-review under responsibility of the Editors

Table 3. Respondents' attitude and perceptions towards Basic Life Support (BLS)

\begin{tabular}{|c|c|c|}
\hline Variables & Descriptions & $\mathrm{N}(\%)$ \\
\hline \multirow[t]{2}{*}{ Ever received formal CPR training } & Yes & $45(40.5)$ \\
\hline & No & $66(59.5)$ \\
\hline \multirow{4}{*}{$\begin{array}{c}\text { Reasons for not receiving any } \mathrm{CPR} \\
\text { training }\end{array}$} & Not a healthcare professional & $9(8.1)$ \\
\hline & I never thought of it & $10(9.0)$ \\
\hline & Costly & $1(0.9)$ \\
\hline & $\begin{array}{l}\text { No information or resources to } \\
\text { join }\end{array}$ & $91(82.0)$ \\
\hline \multirow{2}{*}{$\begin{array}{l}\text { I would like to join CPR training as part } \\
\text { of teachers' training }\end{array}$} & Yes & $109(98.2)$ \\
\hline & No & $2(1.8)$ \\
\hline \multirow[t]{2}{*}{ Rendered medical emergencies } & Yes & $18(16.2)$ \\
\hline & No & $93(83.8)$ \\
\hline Willingness to provide CPR before & Yes & $29(26.1)$ \\
\hline training & No & $82(73.9)$ \\
\hline Willingness to provide CPR after & Yes & $90(81.1)$ \\
\hline training & No & $21(18.9)$ \\
\hline Need to make CPR training mandatory & Yes & $105(94.6)$ \\
\hline for school teachers & No & $6(5.4)$ \\
\hline CPR training would create extra & Yes & $62(55.9)$ \\
\hline demand for curriculum & No & $49(44.1)$ \\
\hline Fear of being sued as a barrier to & Yes & $107(96.4)$ \\
\hline performing CPR & No & $4(3.6)$ \\
\hline Fear of body fluids being passed as a & Yes & $95(85.6)$ \\
\hline barrier for performing CPR & No & $16(14.4)$ \\
\hline Fear of causing injury as a barrier for & Yes & $104(93.7)$ \\
\hline performing CPR & No & $7(6.3)$ \\
\hline Contracting diseases as a barrier for & Yes & $95(85.6)$ \\
\hline performing CPR & No & $16(14.4)$ \\
\hline
\end{tabular}

The final part of the questionnaire examined the attitudes and perceptions toward BLS. More than half $(59.5 \%)$ of the respondents stated that they had not received any formal CPR training previously. Having no information or resources to join CPR training was the most frequently reported reason (82\%) for not being trained. However, most of the respondents did indicate their interest to join the formal CPR training as part of the teachers' training program $(98.2 \%)$ if they were allowed to do so. Besides that, $83.8 \%$ of the respondents had never experienced handling or rendering help during any medical emergencies, leading to their unwillingness to provide CPR before receiving any formal training (73.9\%). Nevertheless, this trend is largely reversed $(81.1 \%)$ as the respondents stated that they would be willing if they had received the proper training. In terms of their perceptions, nearly all the respondents agreed that the CPR training should be mandatory in teachers training programs across Malaysia (94.6\%). However, these respondents were divided in their perceptions as to whether the training might $(55.9 \%)$ or might not $(44.1 \%)$ be an added burden if it were to be implemented 
https://doi.org/10.15405/ejsbs.295

eISSN: 2301-2218 / Corresponding Author: Muhamad Nur Fariduddin

Selection \& Peer-review under responsibility of the Editors

as part of the curriculum. Lastly, in providing CPR during emergencies, the majority of the respondents agreed that barriers such as being sued for negligence (96.4\%), exposure to body fluids $(85.6 \%)$, causing injury to the victim $(93.7 \%)$, and contracting diseases $(85.6 \%)$ were among the main reasons for their unwillingness to not perform CPR during medical emergencies.

\section{Discussion}

CPR knowledge, attitude, and perceptions towards performing BLS during medical emergencies among final year student teachers from various majors in a Malaysian university were investigated. Overall, this study illustrates the alarming trend of low scores in CPR general knowledge despite experiencing training from multiple sources among the final year student teachers. This finding indicates that all student teachers sampled had a low level of knowledge in CPR with zero passes on the knowledge assessment, as reflected in Table 2 with an average score ranging from 4 to 8 , which merely reached the standard passing rate in the AHA guidelines (Hazinski et al., 2010). Although there was no significant association between past CPR certification and knowledge, these results reveal that despite the recent certification of less than six months, all student teachers failed to retain their knowledge, resulting in failing the knowledge test. The result was consistent with other studies showing that, generally, school teachers do not have adequate CPR knowledge (Alharbi et al., 2016; Yang \& Kwon, 2014). This result is also directly related to the absence of previous exposure to any related medical emergencies or ever handling any medical emergencies. As a result, such minimal to no exposure to medical emergencies could lead to limited knowledge and subsequently increases the chances of knowledge deterioration (Al Enizi et al., 2016; Lockey et al., 2016) through a lack of practice.

Retention also plays a role in maintaining adequate knowledge over time. For instance, in this study, nearly half of the student teachers had attended CPR courses in the past five years, and more than half of them acquired their recent certification in less than six months. Nevertheless, research has shown that knowledge loss over time varies according to the nature of the job and professions. For instance, several studies show that healthcare workers' knowledge and skills decrease following three months after training (Bukiran et al., 2014; Ouseph et al., 2015). Alarmingly, despite handling emergencies related to CPR daily, knowledge deterioration still occurs. Like the trend among professionals, this is reflected in the student teachers sampled in this study as they too seemed to experience a high declining rate of knowledge, indicating low retention despite recent CPR certification. This trend was also mirrored in a study conducted among student teachers in Pakistan, which documented a 
https://doi.org/10.15405/ejsbs.295

eISSN: 2301-2218 / Corresponding Author: Muhamad Nur Fariduddin

Selection \& Peer-review under responsibility of the Editors

low retention rate at two months following CPR training (Naqvi et al., 2011). This highlights the ongoing need to determine a suitable duration for CPR training, the number of refresher courses required within a stipulated time to prevent knowledge decay, types of training, and resources to provide the appropriate training based on the standard BLS guidelines.

The second part of this study focused on the attitude and perceptions of the respondents toward BLS training. As reflected in Table 3, more than half had not attended any formal CPR training. The most frequently cited reason for not doing so was the lack of information on formal CPR training instead of financial difficulties and other reasons. In the school setting, most CPR training was conducted by personnel from different vocations, such as firefighters and healthcare professionals (Chien et al., 2016). As stated earlier, the guidelines of the International Liaison Committee on Resuscitation (ILCOR) by the American Academy of Paediatrics and American Heart Association (AHA) strongly recommend the inclusion of the BLS syllabus in the school curriculum (Adedamola \& Chukwudi, 2018). Research has shown that in any medical emergency, it is expected for school teachers to be involved primarily in performing effective CPR on students. In this study, the respondents' attitudes towards providing $\mathrm{CPR}$ during emergencies reveal that the majority are unwilling to provide $\mathrm{CPR}$ before receiving any training. While this is understandable, this trend is reversed as with increased CPR knowledge, they displayed greater willingness and confidence to help others during medical emergencies (Chien et al., 2016; Naqvi et al., 2011). This shows that teachers should acquire adequate knowledge and skills in BLS enabling them to provide effective resuscitation to victims during emergencies in school before the arrival of medical personnel. They are often the first individuals in school to be able to identify cardiac arrest and perform the necessary interventions to save the victim's life (Zinckernagel et al., 2017).

Considering the importance of such lifesaving knowledge and skills for teachers, it is no longer a question of whether to make BLS a mandatory part of the teacher training curriculum, but how soon it can be done. Some teacher training programs, such as Physical and Health Education, have been integrating several subjects such as basic first aid and injury prevention with BLS short courses. To ensure these courses' efficacy, the program utilizes several up-to-date teaching and learning techniques such as using Quality-CPR (QCPR) manikins with simulation and debriefing to allow students to experience real-time medical emergencies (Fariduddin \& Mohd Johar, 2021; Tanaka et al., 2020). With experts' presence as part of the faculty and the resources to implement it, it is imperative that all education courses are restructured to include these courses as mandatory for all final year student teachers across all programs. Despite their perception that this addition would be a burden on the curriculum, 
https://doi.org/10.15405/ejsbs.295

eISSN: 2301-2218 / Corresponding Author: Muhamad Nur Fariduddin

Selection \& Peer-review under responsibility of the Editors

the need for teachers to be proficient in life saving techniques outweighs their hesitation. This highlights the need to restructure the teacher training curriculum.

In any medical emergency in a school setting, it is expected for school teachers to render CPR effectively; nevertheless, the willingness to perform CPR remains questionable and often attributed to various perceived barriers by laypersons in initiating CPR (Bradley \& Rea, 2011). In this study, the fear of medical error and causing injury was the highest underlying the unwillingness to perform CPR during medical emergencies. This fear is understandable as most student teachers had minimal understanding and experiences, as depicted in this study's results. Not knowing the proper techniques would lead to errors in doing chest compression or providing rescue breathing, lack of experiences handling medical emergencies, flawed theories, and lack of practices are significant attributes affecting their confidence and subsequently creating the fear of medical negligence (Kuah, 2011). However, most laypeople are unaware that internationally, performing CPR falls under the Good Samaritan law that protects a layperson (American Heart Association, 2006; Kuah, 2011) from legal repercussions. At the very least, performing CPR even flawed, may likely increase the chances of out of hospital survival rather than not performing CPR at all which will lead to certain death. This study also reported fear of contracting diseases and exposure to body fluids as other barriers for the unwillingness to perform CPR. This may be related to socio-religious and/or socio-cultural inhibitions among Asians in general to physical contact with strangers. This can be related to a study conducted in the United Kingdom, where more than $80 \%$ were willing to initiate CPR on a stranger but the initiation was hindered due to the presence of facial bleeding (Lester et al., 2000). This trend and perception of most student teachers in this study reflects the lack of in-depth understanding of performing CPR. In the chain of survival, it is crucial to ensure the performer's safety before rendering CPR to the victim; however, the AHA guidelines also suggest compression-only CPR as an alternative in performing CPR (Hazinski et al., 2010; Nolan et al., 2010). This method focuses on using hands only with no contact on the victim's mouth to deliver rescue breathing, hence, minimizing exposure to contracting diseases and body fluids.

\section{Conclusion and Implications}

This study found that while the knowledge of teacher trainees regarding CPR is very poor, their attitude towards obtaining CPR training was positive, with a large majority agreeing to join a training if available and believing that CPR should be mandatory for school teachers. Therefore, perceived barriers raised in this study such as not having information regarding available training opportunities and fears of causing injury to others or being sued can be 
eliminated by disseminating correct public health information regarding CPR through the training modules. There is an urgent need to get Malaysian teacher trainees trained in CPR to ensure their readiness in case of medical emergencies in schools. In fact, teachers who are trained can also be certified to conduct trainings for the school students which is in line with the growing global trend of increasing CPR bystanders' population in reducing the out-ofhospital death due to sudden cardiac arrest.

\section{Acknowledgements}

The author(s) declare that there is no conflict of interest.

\section{References}

Adedamola, O. O., \& Chukwudi, O. O. (2018). Retention of cardiopulmonary resuscitation skills in a group of Nigerian school teachers. American Journal of Medicine \& Medical Science, 8(6), 112-116. https://doi.org/10.5923/j.ajmms.20180806.03

Alharbi, M. M., Horaib, Y. F., \& Almutairi, Y. F. O. (2016). Exploring the extent of knowledge of CPR skills among school teachers in Riyadh. Journal of Taibah University Medical Science, 11(5), 497-501. https://doi.org/10.1016/j.jtumed.2016.07.007

Al Enizi, B. A., Saquib, N., \& Zaghloul, M. S. A. (2016). Knowledge and attitudes about basic life support among secondary school teachers in Al-Qassim, Saudi Arabia. International Journal of Health Science, 10(3), 415-422. https://www.ncbi.nlm.nih.gov/pmc/ articles/PMC5003585/

American Heart Association. (2006). CPR: Legal and ethical issues. Life $1^{\text {st }}$. http://www.life1st.com/files/CPR-Legal_and_Ethical.pdf

Bradley, S. M., \& Rea, T. D. (2011). Improving bystander cardiopulmonary resuscitation. Current Opinion in Critical Care, 17(3), 219-224. https://doi.org/10.1097/MCC.0b013e32834697d8

Bukiran, A., Erdur, B., Ozen, M., \& Bozkurt, A. I. (2014). Retention of nurses' knowledge after basic life support and advanced cardiac life support training at immediate, 6 months, and 12-month post-training intervals: A longitudinal study of nurses in Turkey. Journal of Emergency Nursing, 40(2), 146-152. https://doi.org/10.1016/j.jen.2012.08.011

Chien, C. H., Weng, Y. M., Hsu, S. C., Kuo, C. W., \& Chaou, C. H. (2016). Effect of populationbased training programs on bystander willingness to perform cardiopulmonary resuscitation. Signa vitae: journal for intesive care and emergency medicine, 12(1), 6369. https://hrcak.srce.hr/170189

Cuijpers, P. J. P. M., Bookelman, G., Kicken, W., De Vries, W., \& Gorgels, A. P. M. (2016). Medical students and physical education students as CPR instructors: an appropriate solution to the CPR-instructor shortage in secondary schools? Netherlands heart journal, 24(7), 456-461. https://doi.org/10.1007/s12471-016-0838-2

Dwood, S. B., Al-Mosawi, H. S., Khudhair, A. S., \& Al-Mussawi, A. A. (2014). Evaluation of effectiveness of planned teaching programmers regarding basic life support (BLS) among Nursing Staff in Basra General Hospital. International Journal of Nursing, 1(2), 155-166. https://doi.org/10.15640/ijn.v1n2a12 
Fariduddin, M. N., \& Mohd Johar, J. (2021). Retention of Cardiopulmonary Resuscitation (CPR) knowledge among undergraduate teacher student in Malaysian University. Malaysian Journal of Medicine and Health Sciences, 17(1), 3-9. https://medic.upm.edu.my/upload/dokumen/2020123014335701_MJMHS_0224.pdf

Fariduddin, M. N., Wee, L. H., Lilia, H., \& Mohd Johar, J. (2018). Basic-SiM Train-TheTrainer: A model to prepare aviation educators for simulation based first aid learning. ASM Science Journal, 11(1), 24-34. https://www.akademisains.gov.my/asmsj/article/ basic-sim-train-the-trainer-a-model-to-prepare-aviation-educators-for-simulationbased-first-aid-learning/

Fariduddin, M. N., Wee, L. H., Lilia, H., \& Mohd Johar, J. (2019). Structured debriefing in aviation simulation: A qualitative study on cabin crews' BLS training in Malaysia. Malaysian Journal of Medicine and Health Sciences, 15(3), 37-45. https://medic.upm.edu.my/upload/dokumen/2019100108491006_MJMHS_0018_(1).p df

Fariduddin, M. N., Wee, L. H., Lilia, H., \& Mohd Johar, J. (2020). Basic-SiM Train-TheTrainer: A resuscitation training module for cabin crew in Malaysia. Songklanakarin Journal of Science \& Technology, 42(1), 73-80. https://rdo.psu.ac.th/sjstweb/journal/421/11.pdf

John, M. F., Mary, F. H., Michael, R. S., Leon, C., Stephen, M. S., Robin, H., Ricardo, A. S., John, K., Robert, A. B., Farhan, B., Diana, M. C., Edward, C. J., Peter, J. K., Robert, W. N., Mary, A. P., Jeffrey, M. P., Elizabeth, S., Andrew, H. T., Marc, D. B., ... Terry, L. V. H (2010). Part 1: Executive summary: 2010 American Heart Association guidelines for cardiopulmonary resuscitation and emergency cardiovascular care. Circulation, 122, S640-S656. https://doi.org/10.1161/CIRCULATIONAHA. 110.970889

Ghrayeb, F. A., Amro, N. R., Rahseed, O., Yagi, H., Amro, R., \& Amro, B. (2017). Knowledge and attitude of basic life support (BLS) among school teachers in Hebron, Palestine. International Journal of Research in Medical Sciences, 5(6), 2477-82. https://doi.org/10.18203/2320-6012.ijrms20172432

Hazinski, M. F., Nolan, J. P., Billi, J. E., Böttiger, B. W., Bossaert, L., de Caen, A. R., Deakin, C. D., Drajer, S., Eigel, B., Hickey, R. W., Jacobs, I., Kleinman, M. E., Kloeck, W., Koster, R. W., Lim, S. H., Mancini, M. E., Montgomery, W. H., Monkey, P. T., Morrison, L. J., ... Zideman, D. (2010). Part 1: Executive summary: 2010 International consensus on cardiopulmonary resuscitation and emergency cardiovascular care science with treatment recommendations. Circulation, 122(16_suppl_2), S250-S275.

Jain, M., Sharma, L., \& Meena, R. (2016). Cardiopulmonary resuscitation training for medical teachers: Need of the hour. International Journal of Research in Medical Sciences, 7(7), 12655-7. https://www.researchgate.net/publication/348490384_CARDIO PULMONARY_RESUSCITATION_TRAINING_FOR_MEDICAL_TEACHERS_N EED_OF_THE_HOUR

Kuah, B. T. (2011). Medico-legal issues in cardiopulmonary resuscitation and defibrillation. Singapore Medical Journal, 52(8), 643. http://www.smj.org.sg/sites/default/files/ 5208/5208com1.pdf

Lester, C. A., Donnelly, P. D., \& Assar, D. (2000). Lay CPR trainees: Retraining, confidence and willingness to attempt resuscitation 4 years after training. Resuscitation, 45(2), 7782. https://doi.org/10.1016/S0300-9572(00)00170-2 
Lockey, A. S., Barton, K., \& Yoxall, H. (2016). Opportunities and barriers to cardiopulmonary resuscitation training in English secondary schools. European Journal of Emergency Medicine, 23(5), 381-385. https://doi.org/10.1097/MEJ.0000000000000307

Lukas, R. P., Van Aken, H., Mölhoff, T., Weber, T., Rammert, M., Wild, E., \& Bohn, A. (2016). Kids save lives: a six-year longitudinal study of schoolchildren learning cardiopulmonary resuscitation: Who should do the teaching and will the effects last? Resuscitation, 101, 35-40. https://doi.org/10.1016/j.resuscitation.2016.01.028

Make emergency first aid a compulsory subject in schools, gov told. (2019, January 9). Free Malaysia Today. https://www.freemalaysiatoday.com/category/nation/2019/01/ 09/make-emergency-first-aid-a-compulsory-subject-in-schools-govt-told/

Ministry of Education, Malaysia. (n. d.). Statistics of Teachers and Students across Malaysia. http://www.moe.gov.my

Mpotos, N., Vekeman, E., Monsieurs, K., Derese, A., \& Valcke, M. (2013). Knowledge and willingness to teach cardiopulmonary resuscitation: a survey amongst 4273 teachers. Resuscitation, 84(4), 496-500. https://doi.org/10.1016/j.resuscitation.2013.01.023

Naqvi, S., Siddiqi, R., Hussain, S. A., Batool, H., \& Arshad, H. (2011). School children training for basic life support. Journal of the College of Physicians and Surgeons, 21, 611-615. https://doi.org/10.2011/JCPSP.611615

Nolan, J. P., Soar, J., Zideman, D. A., Biarent, D., Bossaert, L. L., Deakin, C., Koster, R. W., Wylie, J., \& Böttiger, B. (2010). European resuscitation council guidelines for resuscitation 2010 section 1. Executive summary. Resuscitation, 81(10), 1219-1276. https://doi.org/10.1016/j.resuscitation.2010.08.021

Ojifinni, K., Motara, F., \& Laher, A. E. (2019). Knowledge, attitudes and perceptions regarding basic life support among teachers in training. Cureus, 11(12), e6302. https://doi.org/10.7759/cureus.6302

Olympia, R. P., Wan, E., \& Avner, J. R. (2005). The preparedness of schools to respond to emergencies in children: A national survey of school nurses. Pediatrics, 116(6), e738e745. https://doi.org/10.1542/peds.2005-1474

Ouseph, B., Mohidin, S., Tabsh, L., \& Al-Hebshi, A. (2015). Nurses' resuscitation performance: Study on the effectiveness of training and support at a teaching hospital in KSA. International Journal of Cardiovascular Disease, 3(4), 21-27. https://doi.org/10.13189/ijccd.2015.030401

Pivac, S., Gradisek, P., \& Skela-Savic, B. (2020). The impact of cardiopulmonary resuscitation (CPR) training on school children and their knowledge, attitudes toward CPR, and willingness to help others and to perform CPR: Mixed methods research design. BMC Public Health, 20, 915. https://doi.org/10.1186/s12889-020-09072-y

Plotnikoff, R., \& Moore, P. J. (1989). Retention of cardiopulmonary resuscitation knowledge and skills by 11-and 12-year-old children. Medical Journal of Australia, 150(6), 296302. https://doi.org/10.5694/j.1326-5377.1989.tb136488.x

Rajeswaran, L., Cox, M., Moeng, S., \& Tsima, B. M. (2018). Assessment of nurses' cardiopulmonary resuscitation knowledge and skills within three district hospitals in Botswana. African Journal of Primary Health Care \& Family Medicine, 10(1), 1-6. https://doi.org/10.4102/phcfm.v10i1.1633

Reder, S., \& Quan, L. (2003). Cardiopulmonary resuscitation training in Washington state public high schools. Resuscitation, 56(3), 283-288. https://doi.org/10.1016/S03009572(02)00376-3 
Tanaka, S., Hara, T., Tsukigase, K., Sagisaka, R., Myklebust, H., Birkenes, T. S., Takyu, H., Kidokoro, Y., \& Tanaka, H. (2020). A pilot study of practice while watch based $50 \mathrm{~min}$ school quality cardiopulmonary resuscitation classroom training: A cluster randomized control trial. Acute Medicine \& Surgery, 7, e455. https://doi.org/10.1002/ams2.455

Tanaka, H., Nakao, A., Mizumoto, H., Kinoshi, T., Nakayama, Y., Takahashi, H., \& Shimazaki, S. (2011). CPR education in Japan--past, present and future. Nihon rinsho [Japanese $\begin{array}{llll}\text { Journal of } \quad \text { Clinical } & \text { Medicine], } & \text { 69(4), }\end{array}$ https://pubmed.ncbi.nlm.nih.gov/21591420/

Yang, Y. J., \& Kwon, I. S. (2014). Nursery teachers' knowledge, attitude and performance ability in cardiopulmonary resuscitation. Child Health Nursing Research, 20(4), 304313. https://doi.org/10.4094/chnr.2014.20.4.304

Zinckernagel, L., Hansen, C. M., Rod, M. H., Folke, F., Torp-Pedersen, C., \& TjørnhøjThomsen, T. (2016). A qualitative study to identify barriers to deployment and student training in the use of automated external defibrillators in schools. BMC Emergency Medicine, 17(1), 1-12. https://doi.org/10.1186/s12873-017-0114-9 